\title{
Individual Tree Crown Methods for 3D Data from Remote Sensing
}

\author{
Eva Lindberg ${ }^{1}$ - Johan Holmgren ${ }^{1}$ \\ Published online: 7 February 2017 \\ (C) The Author(s) 2017. This article is published with open access at Springerlink.com
}

\begin{abstract}
Purpose of Review The rapid development of remote sensing technology has made dense 3D data available from airborne laser scanning and recently also photogrammetric point clouds. This paper reviews methods for extraction of individual trees from 3D data and their applications in forestry and ecology.

Recent Findings Methods for analysis of 3D data at tree level have been developed since the turn of the century. The first algorithms were based on 2D surface models of the upper contours of tree crowns. These methods are robust and provide information about the trees in the top-most canopy. There are also methods that use the complete 3D data. However, development of these 3D methods is still needed to include use of geometric properties. To detect a large fraction of the tallest trees, a surface model method generally gives the best results, but detection of smaller trees below the top-most canopy requires methods utilizing the whole point cloud. Several new sensors are now available with capability to describe the upper part of the canopy, which can be used to frequently update vegetation maps. Highly sensitive laser photo detectors have become available for civilian applications, which will enable acquisition of high-resolution 3D laser data for large areas to much lower costs.

Summary Methods for ITC delineation from 3D data provide information about a large fraction of the trees, but there is still a challenge to make optimal use of the information from the
\end{abstract}

This article is part of the Topical Collection on Remote Sensing

Eva Lindberg

eva.lindberg@slu.se

1 Department of Forest Resource Management, Swedish University of Agricultural Sciences, Umeå, Sweden whole point cloud. Newly developed sensors might make ITC methods cheaper and feasible for large areas.

Keywords Airborne laser scanning (ALS) $\cdot$ Light Detection And Ranging (LiDAR) · Photogrammetry · Segmentation . Individual tree crown (ITC) $\cdot$ Single tree

\section{Background}

Accurate models of vegetation are essential for the development of a sustainable bio-economy based on renewable resources. There is also a need for methods that can be used to frequently update the models to monitor changes. Remote sensing methods should be developed with knowledge of how the methods are going to be used but also with knowledge of the data sources.

Some years before the turn of the century, remote sensing technology for 3D mapping became available for civilian applications. The laser technology had been used since the 1960s, but the availability of advanced Global Navigation Satellite Systems (GNSS) and Inertial Measurement Units (IMU) for survey applications made the laser scanning technology possible. During the beginning of the twenty-first century, there has been a revolution in technology useful for 3D modeling of vegetation covering large land areas. One important driving force in the progress of new remote sensing ap-

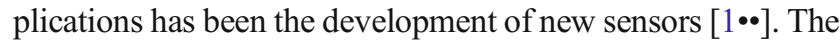
airborne laser scanning (ALS) technology was developed with the primary purpose to create high-resolution digital elevation models of the ground and for mapping of infrastructure, e.g., $3 \mathrm{D}$ city models. There were extensive efforts in the development of algorithms that were used to remove the 'noise' originating from laser returns in the vegetation. Thus, the aim defines the methods. However, once the new 3D data became available to scientists in the field of remote sensing for 
vegetation mapping, the power of the data soon became obvious $[2 \bullet \bullet]$.

ALS data are highly accurate 3D coordinate-measurements of light reflections from the ground, vegetation, and other objects collected from an aircraft. The coordinate measurements are based on the distance derived from Light Detection And Ranging (LiDAR) combined with the orientation of the emitted laser light derived from accurate information about sensor position and orientation obtained from GNSS and IMU. Laser scanning has the advantage over passive optical remote sensing of being comparatively independent of light conditions and image geometry. With the high measurement densities and small footprint sizes (i.e., the surface covered by the laser beam) now available, this means that also objects below the top-most surface can be measured.

Most ALS systems use time-of-flight measurements: a short pulse of laser light is emitted and the time is measured until the reflected light is received. The most wellknown type of ALS data is discrete return data or echo data. The echoes correspond to high power peaks of the backscattered light (Fig. 1). Discrete return ALS data are efficient for analysis of solid surfaces. However, rough or inclined surfaces and surfaces distributed along the laser pulse will give rise to a longer duration of moderately high power of the backscattered light. To analyze this in detail, the intensity envelope, known as waveform data in airborne laser scanning, can be recorded. Waveform laser scanning data are measurements of the power of the backscattered light at regular time intervals. The reflecting surfaces may be characterized from the waveform by the intensity (i.e., amplitude) and echo width (i.e., duration) of the corresponding peaks.

The natural vegetation has a complex structure compared to artificial objects. The ideal situation would be a system that could measure every part of each tree, e.g., stem, branches, needles, and leaves. The laser systems are close to this situation. Since the systems were originally designed to emit pulses and receive at least some energy from the ground, they are usually sensitive enough to measure all parts of the vertical vegetation structure. However, the vegetation causes an attenuation of the signal that is a function of the penetration depth [3].

Another approach to obtain detailed 3D data describing the tree crowns is derivation of photogrammetric point clouds. The development of computer vision algorithms now makes it possible to automatically produce 3D models using matching of overlapping aerial images. This triangulation technique is only possible if the same feature can be identified in two or several images that cover a common area, in other words solving the corresponding problem. To identify the same feature in several images it must be illuminated with sun light. The position errors increase with the distance to the object, i.e., the flight altitude, and decrease with the
Emitted pulse

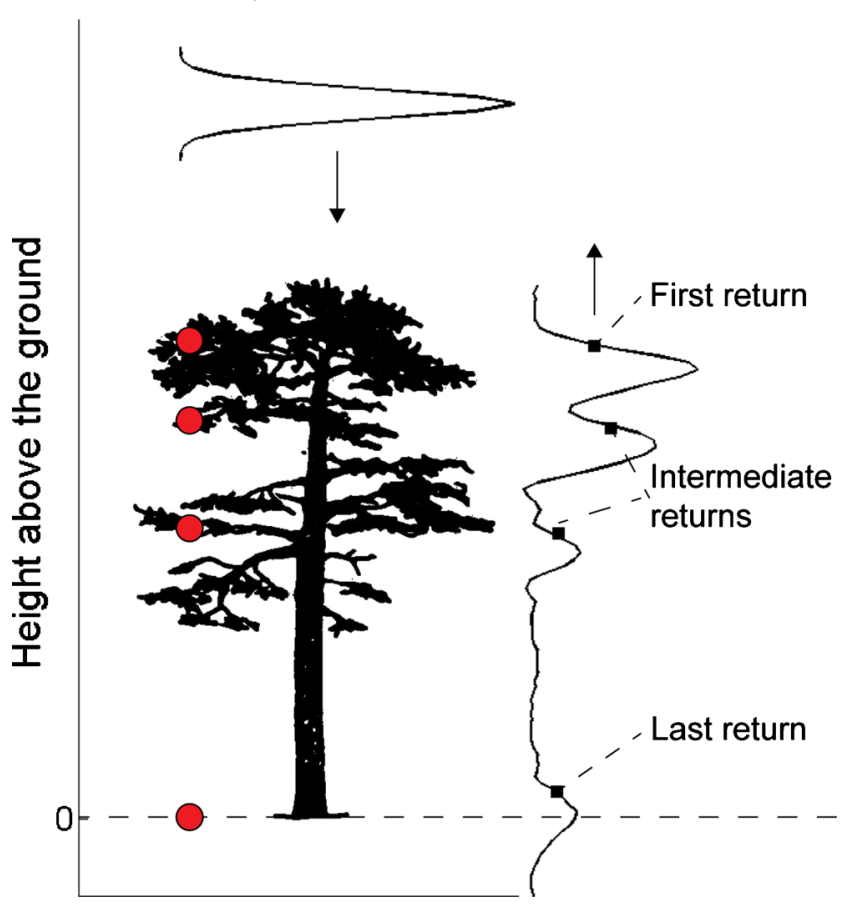

Fig. 1 The emitted pulse is reflected from different surfaces, resulting in a waveform that can be used to derive discrete returns

length of the base-line, i.e., the distance between the positions of exposures. The corresponding problem becomes more difficult with low ratio between the distances to the object and base-line because world features are then viewed from different angles and thus appear differently in the images. The corresponding problem is also more difficult in forested areas because other trees may be in the line of sight. This makes it difficult to measure the sides of tree crowns, small trees between tall trees, and the ground between trees. The corresponding problem becomes easier with lower flight altitudes and several images overlapping the same area, for example, using images acquired from Unmanned Aerial Vehicles (UAV).

In addition to at least two overlapping images, stereophotogrammetric techniques require known camera interior and exterior orientations. The interior orientation is mainly the position of the perspective center and the radial distortion curve and is determined through a camera calibration process. The exterior orientation is the location and angles (i.e., the relationship between image and object space) and is determined from GNSS and IMU measurement and block triangulation using ground control points with known positions. The block triangulation is often combined with bundle block adjustment, which determines the relative orientation of multiple images by minimizing the errors at image points that appear on several 
images but have unknown ground positions as well as errors at the ground control points and the perspective centers [4].

The images can then be matched together to identify the same objects in several images. Commonly used matching approaches are feature-based matching and semi-global matching [5]. Feature-based matching derives a vector of features around each object in the different images and connects the points by finding the nearest neighbor in feature space. Semi-global matching is based on minimization of a pixelwise matching cost with an additional smoothness constraint that penalizes disparity changes [6]. Semi-global matching can generate very dense point clouds with a resolution corresponding to the original images, but it requires more computational resources than feature-based matching [5]. Following the matching, the $3 \mathrm{D}$ coordinates are calculated through space-forward intersection, which is based on the light rays through the two camera centers passing through the corresponding image points and intercepting at the same ground point [4]. Compared to ALS data, the disadvantages are that photogrammetric point clouds generally appear smoother and might have problems with occlusions and artefacts from mismatches [7] and only the top-most surfaces can be represented. An advantage is that the points can be assigned colors from the corresponding pixels in the images.

UAVs are promising for detailed mapping of vegetation although they cover smaller areas per time unit than conventional airplanes [8]. As an example, a UAV flight at $200 \mathrm{~m}$ above ground level resulted in images with pixel size $5 \mathrm{~cm}$ that were used to derive point clouds and a surface model where trees were identified with local maxima detection [9].

3D data are now available from a diverse set of sensors and sensor platforms: ALS, aerial images collected using airplanes, stereo-images collected from satellite systems, and images collected from UAVs. Several of these techniques are becoming useful for vegetation mapping because digital elevation models (DEM) have been produced by ALS for large areas. This increases the usefulness of techniques for vegetation mapping that can produce 3D data for the upper parts of tree canopies because the data are normalized by subtraction of an already existing DEM. Thus, this enables the use of other data sources than ALS to update vegetation heights, for example, photogrammetry from aerial images or satellite images.

\section{Delineation Methods}

\section{Overview}

Individual tree crown (ITC) methods are algorithms to delineate tree crowns from raster images or high density point clouds. They are used for estimation of stem attributes such as tree height, stem volume, and tree species and to produce extensive lists of geo-located trees based on the delineated tree crowns. Many algorithms have been developed for extraction of individual trees, e.g., [10••] and all methods are not covered in this article. However, the main types of algorithms are described and examples are presented. The algorithms can be divided into surface model methods, where the point cloud is simplified into a raster, and 3D methods, which utilize information from the whole point cloud, where the 3D methods can be further divided into cluster methods applied to point data and voxel-based methods.

To identify individual trees from a point cloud, each tree crown must contain several points, which defines the required minimum point density. The aim is usually to delineate only points from the canopy, which means that the height above the ground of each point must be calculated and a DEM is needed. The height above the ground is also needed to estimate tree height and other tree attributes. Although the DEM is important for the tree crown delineation, this review does not cover classification of ground points and derivation of the DEM, which has been reviewed in other studies, e.g., [11].

\section{Surface Model Methods}

Automatic detection of individual trees from ALS data can be done by deriving a surface model representing the upper contour of the canopy and identifying local maxima in the surface as treetops. A digital surface model (DSM) is first created and the value of a raster cell is set to the maximum height of laser return within the raster cell. The DEM is subtracted from the DSM to obtain a normalized DSM (nDSM) with canopy heights, a so-called canopy height model (CHM) (Fig. 2). One advantage of this approach is that $2 \mathrm{D}$ image analysis methods can be applied. Several image analysis algorithms for detection of trees in 2D aerial images were developed already before 3D measurements became available by the introduction of ALS [12, 13]. For example, treetops were assumed to be more illuminated by sun light compared to sides or spaces between tree crowns. Also, the illumination and tree crown geometry was modeled in $3 \mathrm{D}$ to derive $2 \mathrm{D}$ templates that were matched with the 2D aerial images [14]. The image analysis algorithms that had been adapted to tree detection in aerial images were also used for 3D data from ALS, mostly by deriving CHM images. For example, local maximum filters were used to detect treetops. It was also possible to delineate tree crowns using algorithms already developed for aerial images $[15,13]$. However, the 3D data of tree crowns obtained from ALS made it possible to make assumptions and use 3D models of the tree crown geometry to improve the delineation.

The first sub-problem is how to create a surface that describes the tree crowns. The laser pulses penetrate through the canopy, which is an advantage because data are available also from trees in the lower parts of the vegetation layer and from 


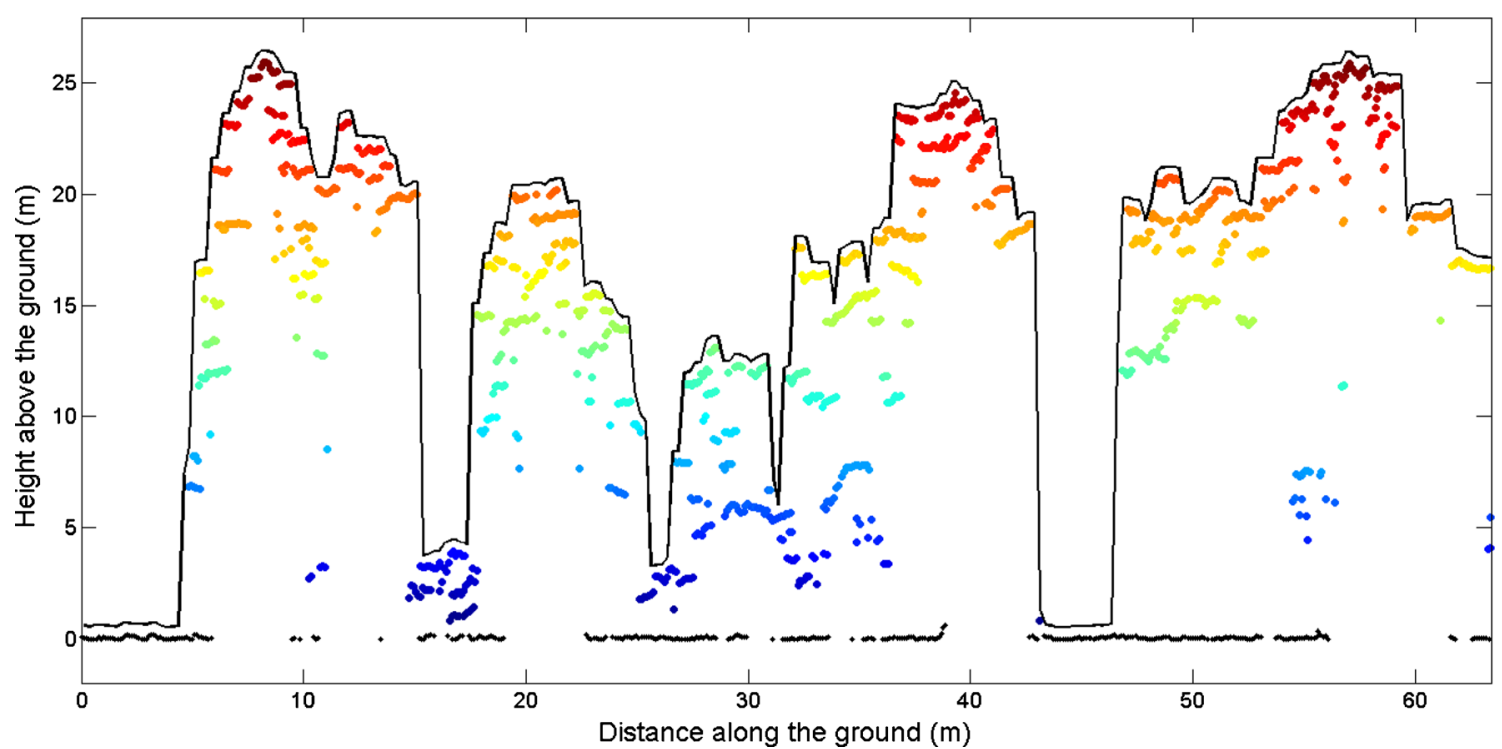

Fig. 2 Side view of a $2 \mathrm{~m}$ wide transect of ALS data from a forest with a CHM derived from the ALS data

the ground. However, if the aim is to describe the upper contour of a tree crown, the penetration will add noise that will make it more difficult to separate trees that are close to each other. Another consideration is returns from the ground and objects close to the ground inside a tree crown because of the penetration of the laser pulses. The question arises whether the interpolation should be performed using all returns or only returns from the canopy. Also, if height values are interpolated outside tree crowns there is a higher risk that small trees are hidden below the interpolated surface. Therefore, a canopy raster could first be created using morphology operations in order to create a canopy map without holes inside tree crowns. This map could then be used to only interpolate values inside canopies. One way is to use the maximum laser height within each raster cell and then use triangulated irregular network (TIN) interpolation to set values for empty raster cells [1••]. Also, an elastic surface can be applied using active contour algorithms [16]. However, there are several decisions to make, for example what cell size should be used. The choice of cell size depends on the size of the tree crowns and the measurement density. It is not easy to evaluate the result because the canopy is not easy to define. It is important to keep in mind that information is lost after any kind of interpolation because the $3 \mathrm{D}$ data is then represented by a surface, thus data below the surface are discarded.

The second sub-problem when applying surface models is how to know the optimal scale. A multiscale approach is needed if there is a variable tree crown size. The optimal selection of scale depends on the size of the trees that are to be measured and is therefore not known in advance. Trees can be detected by finding local maxima in the surface model. However, several local maxima could be found in the tree crown of one individual tree.
One way to select the scale is to use a variable window size for the maximum filtering that is based on empirically determined relationships between tree height and crown diameter [17]. In that case, the tree detection results are only based on the crown diameter prediction and there could be large errors for tree crown diameter predictions from tree height. It is possible to use data in the neighborhood to estimate the shape of the tree, information that could be useful for the selection of scale. However, the neighborhood should be from the same individual tree crown area which is not known. Another way is to smooth the surface with Gaussian kernels with different sigma values (i.e., scale parameters). The un-smoothed surface typically has a structure with local height maxima within tree crowns. The number of local maxima decreases if the sigma value increases with sequential smoothing with Gaussian kernels. According to the scale-space theory, no new maxima are introduced when the scale parameter is increased [18].

Segmentation of the smoothed surface models from different scales will result in overlapping segments. The best segment out of the overlapping segments from different scales can be selected using the 3D data within segments. One solution is to fit a parabolic surface to the $3 \mathrm{D}$ data and select the scale resulting in the smallest residuals [16]. However, multiple criteria can be used, for example size, circularity and convexity [19], or laser-derived tree crown curvature [20]. The multi-scale problem has also been solved using wavelet analysis [21].

The third sub-problem is delineation of tree crowns. The goal is to create polygons that define the boundary between different tree crowns and between tree crowns and other objects, for example, the ground. This step is usually combined with the previous step and is an important part of the task to select an optimal scale. The 3D data within a segment are used 
in order to estimate if the segment is only a part of a tree crown, contains more than one tree crown, or only contains one individual tree crown. One simple method to delineate tree crowns is to use the watershed algorithm that can be explained by the water movements through a landscape. The rain water falls everywhere and the water moves in the direction with steepest slopes. For the tree crown segmentation, the movement is instead upwards to local maxima that are assumed to be treetops. A starting point is placed in every raster cell above a height threshold. A path is placed from each starting point by iteratively moving to the neighbor raster cell with the highest value until a local maximum is reached. The starting points that reach the same local maximum define a segment.

There are several steps of a tree detection algorithm with potential errors in each step. For example, a very good scale selection strategy is not useful if the surface model includes large errors. Information is lost in each processing step. Therefore, a good strategy is to use the original data until it is possible to make an object-dependent representation and generalization [22]. One proposed solution is to use geometric tree models that are fitted to laser data, for example, ellipsoid models [23]. The models were centered at every raster cell location. Tree height was set to the height of a CHM. The best value of the model parameter crown radius (i.e., width of the ellipsoid) was not known and therefore several radii were tested. The test yielding the highest correlation with laser data was saved for the raster cell where the geometric model was centered. A correlation surface was created through tests at all raster cells with a canopy height value above a threshold. The correlation surface was then used as input to watershed segmentation. Finally, segments were merged based on model tests using the same geometric tree crown model. Individual trees have also been detected using the Hough transform, for which cones were used as the geometric tree model [24].

Algorithms using a CHM as input will typically not detect trees below other trees because data from these are lost already when the CHM is created. It is however possible to use surface methods sequentially from the top layer of the canopy and downwards by excluding tree crowns delineated in the topmost canopy layer from the point cloud to reveal data from lower canopy layers [25]. First, a preliminary segmentation was performed based on the CHM that had been created from the complete dataset. The vertical distribution of laser returns was then analyzed to find the next vegetation layer by identifying a local minimum in each segment and excluding the ALS data above the local minima from the point cloud that was used to produce a new CHM using only the lower layer. The process continued until no further CHM from lower vegetation layers could be created $[25,26]$.

Photogrammetric point clouds have been used for forestry applications, but most analysis has been done with area-based approaches where summary measures such as mean tree height and mean stem volume are calculated for a defined area. However, it has been proposed that ITC delineation from photogrammetric point clouds might be possible thanks to the recent improvements in image matching algorithms [7]. The approaches developed this far have been based on derivation of a surface model from the point cloud: local maxima detection and region growing around the local maxima $[7,27,28]$ or delineation of homogenous areas based on color information combined with height and slope of the surface model [29].

\section{D Methods}

Since parts of the laser light can pass through the canopy, the ALS data include measurements of surfaces below the topmost canopy layer. The measurements originate from the ground and other objects, including lower parts of the tree crowns or small trees and shrubs in lower canopy layers. This may be used to delineate individual tree crowns in three dimensions from ALS data.

A common approach is to first delineate the trees in the topmost canopy layer from a CHM or another surface model and then use this information when analyzing the whole point cloud. The delineated tree crowns in the top-most canopy layer may be used as initial values when delineating tree crowns and shrubs from the point cloud or the ALS returns assigned to the tree crowns may be excluded to enable analysis of the canopy structure below. Another common approach is to divide the point cloud into horizontal slices of a certain vertical thickness, analyze each slice separately to identify tree crowns in each slice, and aggregate the delineated tree crown slices to define three-dimensional tree crowns [30, 31].

If the measurement density is high enough, the tree stems below the top-most canopy can be identified. For very high density, at least 50 returns per square meter, methods developed for ground-based laser scanning have been applied such as skeletonization of the returns from the tree stems and estimation of the stem diameter from returns classified as originating from the stem [32] and extraction of the returns from tree stems based on their higher intensity followed by segmentation of the tree stems starting from the bottom [33]. In many cases, the measurement density is too low to allow estimation of the stem diameter from the point cloud, but the positions of the stems can be determined. An application of this is to first determine an approximate number of stems by clustering of the ALS data below the top-most canopy layer and then use the estimated stem number for delineation of individual tree crowns. This has been done with various 3D methods: kmeans clustering applied to the whole point cloud [34], watershed segmentation applied to the point density in voxels derived from ALS data [35], and a normalized cut algorithm applied to the distance between voxels and the mean intensity and echo width derived from waveform ALS data [36]. 
Delineation of the point cloud may be done with k-means clustering where the ALS returns are iteratively partitioned into $\mathrm{k}$ clusters in which each observation is assigned to the cluster with the nearest mean. The clustering requires initial positions of the clusters that can be derived from local maxima in a CHM or by other means of identifying treetops from the ALS data [37, 38]. By scaling the distances in vertical and horizontal direction differently, the shape of the clusters can be controlled to make them more elongated in the vertical direction. To make further use of the information about the treetops that are delineated from the surface model, the clustering can be adapted to increase the probability to assign ALS returns within each treetop to the corresponding cluster and to assign ALS returns close to the top-most canopy surface to the tallest trees [34].

The mean-shift algorithm is another clustering algorithm that divides data into groups by locating maxima of the point density within local regions (i.e., within kernels). The meanshift moves a kernel iteratively from the position of each point towards the local density maximum. One cluster is made up of points for which the kernel ends up in the same local density maximum. The only parameter is the kernel bandwidth, although that parameter is critical for the results. Variable kernel bandwidth for different forest layers has been suggested as a means to allow smaller clusters close to the ground and larger clusters in the top-most canopy [39]. Mean-shift assumes that each tree crown corresponds to a density maximum, which might not be true. For many tree crowns, most of the ALS data are located on one side and there is often no clear density minimum between tree crowns.

Normalized cut is an algorithm to divide data into groups based on the total feature dissimilarity between the different groups as well as the total feature similarity within the groups [40]. Normalized cut has been applied to voxels derived from ALS data to delineate tree crowns. The features were the distance between the voxels and the mean intensity and mean echo width from calibrated waveform ALS data within each voxel [36]. Normalized cut has also been applied to ALS data with spectral attributes originating from aerial images [41] or hyperspectral images [42]. The normalized cut has resulted in a larger fraction of identified trees, especially for trees below the top-most canopy layer, but also a slight increase in erroneously delineated trees compared to watershed segmentation of a CHM [36].

The delineation may also be done with region growing. Region growing from the treetops and downwards has been done for the whole point cloud [43] and for voxels [44, 45•]. Lee et al. [43] delineated the point cloud by first finding the top-most ALS returns within a search radius and defining them as treetops. The delineation was done for one ALS return at a time by finding the top-most return not assigned to any tree crown, identifying the nearest neighboring return assigned to a tree crown, and adding the return to that tree crown. Vega et al. [46] presented a similar delineation method but with merging of segments based on different scales. Vaughn et al. [44] delineated voxels derived from ALS returns extracted from full waveform data with a similar algorithm. The delineation started by finding voxels containing ALS data in the top-most layer of voxels and identifying them as treetops. For the next layer, voxels containing ALS data were either assigned to the nearest neighboring tree crown or identified as a new treetop if no tree crown was in the vicinity. A similar algorithm based on region growing of voxels [45•] identified treetops by finding voxels with a certain open space above, a cluster of ALS returns in the neighborhood and not spatially attached to another treetop. Region growing from the bottom has been done by Lu et al. [33] starting with the lowest returns classified as tree stems and adding nearby returns with restrictions for the distance in 2D and 3D. Finally, all returns were assigned to the different trees by adding one return at a time to the nearest tree crown.

An alternative to full 3D delineation of the point cloud is to first divide the point cloud into horizontal slices, do the delineation in each slice separately, and then join the resulting delineated tree crown slices along a vertical axis. This has been done with 2D k-means clustering in each slice and subsequent merging of clusters that overlap along the vertical direction [30] and by deriving the horizontal contours of the trees from a region-based level set method and constructing a 3D canopy surface by stacking the contours on top of each other [31]. Dividing the point cloud into slices is an intuitive approach and can be implemented in a computationally efficient way, but it does not make optimal use of the geometric information in the point cloud since it simplifies the data before delineating the tree crowns in the vertical direction.

\section{Comparison of Methods}

Methods for ITC delineation have been compared in different forest conditions $[45 \bullet, 47 \bullet, 48 \bullet, 49 \bullet]$. Comparison in two boreal forest stands gave varying success depending on the method [47•]. However, the result is determined by whether the method is designed for the forest type and the setting of appropriate parameter values. In another comparison in different forest types, different methods gave similar results overall [48•]. Additionally, the choice of method depends on the aim of the ITC delineation. To detect a large fraction of the tallest trees, a surface model method generally gives the best results, but detection of smaller trees below the top-most canopy requires methods utilizing the whole point cloud [45•, 49•]. Kaartinen et al. [47•] suggested that methods that provide good results for the top-most canopy are suitable for general mapping of forests while methods that accurately record the diameter distribution are more suitable for forest inventory. The choice of methods also depends on properties of the data, for example, the sensor and measurement density. Methods 
using the whole point cloud generally require higher measurement density than surface-based methods since the risk of occlusion is higher for objects below the top-most canopy. As a rule, a higher measurement density has a greater chance of providing information about small objects, which means that smaller trees and properties of the tree crowns can be more accurately described from data with a higher measurement density.

\section{Applications of the Delineated Tree Crowns}

\section{Estimation of Forest Variables}

The next step after tree crown delineation is estimation of attributes for individual trees. It is usually the physical properties of tree stems that are important for forestry applications. There is however a relationship between crown and tree stem. According to the pipe model theory, a unit amount of leaves is provided with a pipe whose cross section area is constant. The pipe has both a vascular and mechanical function and connects the leaves to the stem base. It is therefore possible to observe a correlation between stem cross section area and the weight of the canopy above [50]. Thus, empirical models can be used to predict stem attributes from 3D measurements of tree crowns obtained from airborne sensors if reference data are available to establish these empirical models. Tree height can be estimated by finding the maximum 3D measurement within the tree crown. However, in this case reference data are also needed because the maximum height of laser returns is typically an underestimation of the tree height $[16,51,52]$. The reason could be penetration of laser pulses into the canopy before a return is detected and the lack of laser returns located exactly on the treetop. Co-registration of the delineated tree crowns and trees measured in the field must consider and adjust positioning errors in the field data [53-55].

For forestry applications, the estimates of individual trees are usually aggregated to plot/raster cells or forest stands. Sometimes the aggregation is presented as the final result which could be misleading. There is no guarantee that all trees have been detected and there might be false trees, so-called omission and commission errors, respectively. The proportion of detected trees depends on the forest structure [16, 48•]. Therefore, the estimation methods should include correction of errors due to both omission and commission errors. The idea to predict tree attributes for tree clusters instead of individual trees has therefore been proposed $[1 \bullet \bullet$. A nonparametric method with utilization of 3D laser data within a segment has been applied to estimate the number of trees within a segment. A nearest neighbor method was then used at a raster cell level to correct the tree number according to the estimated tree number [56, 57]. Probability models have been used to estimate tree species and stem number within segments using data from the tree crown delineation. Conditional regression equations were then used to estimate stem diameter. The estimates were applied in a sampling context that produced unbiased estimates within strata [58]. Another approach has been to use nearest neighbor estimation methods to impute segments that contain zero, one, or several trees. All field-measured trees in the plots were therefore linked to a tree crown segment when the reference database was created. This approach was named semi-ITC [59]. The semi-ITC approach is simple to apply and several variables can be estimated simultaneously. The imputation of segments that contain one or several tree stems is necessary if the predicted tree stems are to be used for further analysis, for example if automatically measured tree stems will be used for simulations in order to predict wood product assortments [60]. A semi-ITC approach can also be applied to tree crown segments delineated from photogrammetric point clouds [61].

\section{Classification of Tree Species}

A great advantage of individual tree methods is that tree species classification of individual trees may be done from the ALS data (Fig. 3), which is particularly useful for forests with a mixture of tree species. Tree species classification of individual tree crowns delineated from surface models derived from discrete return ALS data can be done based on the first moments of the height and intensity data distributions within each tree crown segment [62] as well as other variables derived from the height and intensity data distributions, from the fraction of first returns, and from a parabolic surface fitted for each tree crown segment [63], which has also been confirmed by later studies $[64,65]$. By describing the extent of the tree crowns with alpha shape metrics, additional variables can be derived to both classify tree species and estimate DBH [66, 67]. This kind of analysis utilizes more details of the ALS data together with the knowledge of the shape of treetops and tree crowns $[63,68]$. For ALS data with high density, line features can be derived inside the tree crowns to represent hypothetical branches that can be used for tree species classification [69]. Tree species classification of individual trees has also been done with good results from a combination of discrete return ALS data and multi-spectral aerial images $[66,70]$ or hyperspectral aerial images [71]. Recent technical development includes multispectral laser scanning (i.e., laser light with several wavelengths), which has the potential to improve tree species classification [72].

Tree species classification may also be done from waveform ALS data. Since the waveform data describe the reflected light in more details, it is possible to derive the intensity and echo width and also the backscatter cross-section if calibration data are available. Tree species classification of individual tree crowns delineated from surface models is improved by including variables derived from the echo width, 
Fig. 3 ALS data from a pine (left) and a spruce (right); units in metres

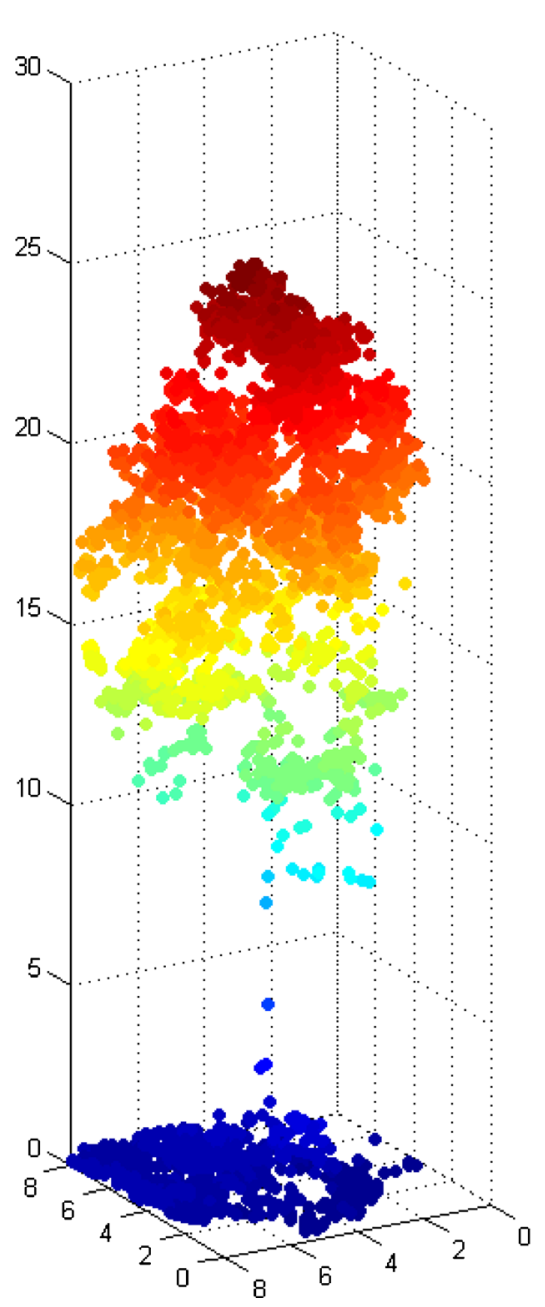

the backscatter cross-section, and the total number of echoes within the tree crowns $[73,74]$. Tree species classification may also be done for individual tree crowns delineated in three dimensions. So far, this has been done for waveform ALS data based on intensity and echo width [34, 75]. Additionally, the Fourier transform may be applied to the waveform to derive information about the distribution of returned intensity values along the pulse, which is related to the positions of branches in the tree crowns. This approach has been shown to improve the tree species classification [44].

\section{Habitat Analysis and Urban Mapping}

One application of ITC methods is for mapping of vegetation in urban environments. The ability to derive properties of the individual tree crowns can provide information about tree species and other properties of the trees such as tree height, crown diameter, and crown length. However, urban environments often have a broad mix of tree species and trees of different heights and crown shapes, which makes the ITC analysis more challenging [76]. Another application is for habitat analysis, where detailed information about the trees can provide information that is not otherwise available for large areas about the height distribution or layering, tree species composition, and site condition [77] or standing dead trees and burnt forest [78].

\section{Outlook}

\section{Multispectral ALS}

Until recently, operational ALS systems for terrestrial mapping have used only one light wavelength [79]. However, a new multispectral ALS system is now available, where measurements are done with three different wavelengths simultaneously: $1550 \mathrm{~nm}$ (i.e., SWIR), $1064 \mathrm{~nm}$ (i.e., NIR), and $532 \mathrm{~nm}$ (i.e., green) [80]. Common wavelengths in earlier ALS systems for mapping of land areas have been NIR and SWIR laser light [81]. Laser scanners with visible green wavelength are used for hydrographic and bathymetric applications [81], sometimes with red and infrared wavelengths in addition 
to the green wavelength [81]. In order to decrease the energy density for eye safety reasons, the beam divergence is usually greater for green laser scanners $(0.7-1.0 \mathrm{mrad})$ than for NIR and SWIR laser scanners (approximately $0.2-0.5 \mathrm{mrad}$ ), meaning that the footprint is larger at the same distance from the scanner [80, 82-84]. The different footprint sizes lead to different spatial averaging, which may provide complementary information for the different wavelengths, but also cause co-registration problems when combining the data positions. Additionally, the new multispectral ALS system emits the different wavelengths at different angles resulting in separate scan lines and differences in positions of measurements [80].

A combination of green and NIR/SWIR wavelengths is likely to be useful for vegetation analysis since the reflectance of healthy plants is highest in the NIR spectrum and around $550 \mathrm{~nm}$ in the visible spectrum due to the lower absorption of their chlorophyll content. From interpretation of aerial images, it is well known that different tree species have somewhat different reflectance spectra [85]. A multispectral laser scanner provides spectral as well as geometric information about the vegetation [86], providing a potential for detailed analysis of tree species, forest succession, and forest health status. Early results show the potential of multispectral laser scanning for classification of tree species both for the new system with three wavelengths [72] and when combining laser data from three separate ALS systems [87]. However, the optimal combination of wavelengths for laser reflectance is still being evaluated for measuring forest vitality and succession [86], phenology [88], plant physiology and photochemical reflectance $[89,90]$, and nitrogen stress [89-91].

\section{High Resolution Data from New Sensors}

Most commercial airborne laser scanning systems that have been used until now emit a pulse with a small divergence and one or several return pulses are detected by a single photo detector. The coverage of $3 \mathrm{D}$ data is obtained by the scanner together with the movement of the aircraft. New detectors are now becoming available for commercial use, detectors that are very sensitive, with the ability to detect single photons, and are placed in a matrix. Different parts of the returned pulse can be detected by individual detectors of the matrix. Due to this, a high measurement density can be obtained also from high altitudes. This means that ITC methods for 3D data will become more feasible for large forested areas. Two different systems were recently evaluated in North America: the Sigma single photon technology and the Harris IntelliEarth ${ }^{\mathrm{TM}}$ Geospatial Solution Geiger-mode LiDAR. The first system produced 25 points per square meter from an altitude of $7540 \mathrm{~m}$ above ground and the latter system produced 23 points per square meter from an altitude of $2293 \mathrm{~m}$ above ground level. As a comparison, typical conventional linear systems currently produce 2-4 measurements per square meter from a flight altitude of $2200 \mathrm{~m}$ above ground or lower [92].
Also, the flight speed can be higher with the new systems, which together with high flight altitude means that the coverage rate $\left(\mathrm{km}^{2} / \mathrm{h}\right)$ can increase up to 30 times compared with conventional linear systems [93]. Research is however needed in order to find out the suitability of the data for ITC methods and adapt the methods to the new data. The matrix detectors also make it possible to use flash lasers. These lasers illuminate the entire scene and a distance image is recorded for each emitted pulse. It is only possible to measure at shorter distances compared with scanning systems but the design without scanner will probably enable construction of systems that are small and not very expensive. These systems are suitable for small and flexible systems, for example, mounted on UAVs.

\section{Conclusions}

Methods for ITC delineation have been continuously developed ever since dense point clouds from ALS became available in the late 1990s. Most approaches have been based on interpolation of a surface model from the point cloud, but various methods to utilize the whole point cloud are also common. Methods based on surface models are robust and can delineate a large fraction of the tree crowns in the top-most canopy, especially in boreal coniferous forest. However, interpolation of the point cloud also means that some information is lost. Methods that utilize the whole point cloud provide more information about trees and shrubs below the top-most canopy, but generally require more parameters and pose a greater risk of dividing tree crowns into more than one segment. The choice of method depends on the application and whether the primary goal is to accurately describe the tallest trees in the top-most canopy or to derive information also about smaller trees below the top-most canopy. For some applications such as logging or biomass assessment, the tallest trees are most important, but for applications such as understory regeneration or habitat analysis, the smaller trees are also of interest. A surface model describes the top-most canopy and the delineation methods that have been used, for example watershed segmentation, make use of geometrical properties of the tree crowns (i.e., that the treetop is the highest point of a tree and the surrounding tree crown height gradually decreases). Most surface methods also include selection of an appropriate scale. However, most 3D methods have not used knowledge about the geometrical properties of the tree crowns and have not included scale selection. Therefore, there is still a challenge to develop such methods to make optimal use of the information from the whole point cloud.

The ongoing rapid sensor development will make collection of dense 3D point clouds faster and cheaper. This means that dense point clouds will probably be available for larger areas, which will enable delineation of individual tree crowns. This will have importance for mapping of forests and 
vegetation in general. Information that can be derived with higher accuracy from ITC delineation includes estimates of the height or diameter distribution and the tree species. Recent technical development also includes a multispectral ALS system, which will probably enable more accurate tree species classification. Additionally, development of new airborne and space-borne optical sensors will make highresolution images more common and enable derivation of dense point clouds by stereo-photogrammetric techniques, which will provide users with more frequently updated 3D models.

Acknowledgements We would like to thank our colleagues and partners with whom we have had the opportunity to collaborate about this topic and who have contributed to the knowledge presented in this work.

\section{Compliance with Ethical Standards}

Conflict of Interest Dr. Lindberg and Dr. Holmgren declare that this study was financed by The Swedish Research Council Formas through the projects "Habitat suitability information from airborne laser scanning data" and "Precision forestry for the future: enhanced forest management by optimized tree selection in thinning operations".

Human and Animal Rights and Informed Consent This article does not contain any studies with human or animal subjects performed by any of the authors.

Open Access This article is distributed under the terms of the Creative Commons Attribution 4.0 International License (http:// creativecommons.org/licenses/by/4.0/), which permits unrestricted use, distribution, and reproduction in any medium, provided you give appropriate credit to the original author(s) and the source, provide a link to the Creative Commons license, and indicate if changes were made.

\section{References}

Papers of particular interest, published recently, have been highlighted as:

- Of Importance

•- Of Major Importance

1.• Hyyppä J, Hyyppä H, Leckie D, Gougeon F, Yu X, Maltamo M. Review of methods of small-footprint airborne laser scanning for extracting forest inventory data in boreal forests. Int J Remote Sens. 2008;29(5):1339-66. doi:10.1080/01431160701736489. Review of methods for extracting forest inventory information from small-footprint ALS data, mainly in the boreal forest zone.

2.• Hollaus M. 3D point clouds for forestry applications. Österreichische Zeitschrift für Vermessung und Geoinformation (VGI). 2015;103(2 + 3):138-50. An overview of state of the art 3D data-acquisition systems and derivation of forestryrelated information from the derived 3D points clouds.

3. Chasmer L, Hopkinson C, Treitz P. Investigating laser pulse penetration through a conifer canopy by integrating airborne and terrestrial LiDAR. Can J Remote Sens. 2006;32(2):116-25.
4. Aber JS, Marzolff I, Ries J. Small-format aerial photography: principles, techniques and Geoscience applications. Amsterdam, The Netherlands: Elsevier Science; 2010.

5. Haala N. Benchmark on image matching: European Spatial Data Research. 2014 Contract No.: 64.

6. Hirschmüller H. Stereo processing by semiglobal matching and mutual information. IEEE Trans Pattern Anal Mach Intell. 2008;30(2):328-41. doi:10.1109/tpami.2007.1166.

7. St-Onge B, Audet FA, Begin J. Characterizing the height structure and composition of a boreal forest using an individual tree crown approach applied to photogrammetric point clouds. Forests. 2015;6(11):3899-922. doi:10.3390/f6113899.

8. Fritz A, Kattenborn T, Koch B. UAV-based photogrammetric point clouds - tree STEM mapping in open stands in comparison to terrestrial laser scanner point clouds. In: Grenzdorffer G, Bill R, editors. Uav-G2013. International Archives of the Photogrammetry Remote Sensing and Spatial Information Sciences, 2013. 141-6.

9. Zarco-Tejada PJ, Diaz-Varela R, Angileri V, Loudjani P. Tree height quantification using very high resolution imagery acquired from an unmanned aerial vehicle (UAV) and automatic 3D photoreconstruction methods. Eur J Agron. 2014;55:89-99. doi:10.1016/j.eja.2014.01.004.

10.• Zhen Z, Quackenbush LJ, Zhang LJ. Trends in automatic individual tree crown detection and delineation-evolution of LiDAR data. Remote Sens. 2016;8(4):333. doi:10.3390/rs8040333. Review of trends in individual tree crown detection and delineation research from 1990-2015 from several perspectives-data/forest type, method applied, accuracy assessment and research objective-with a focus on studies using ALS data.

11. Meng X, Currit N, Zhao K. Ground filtering algorithms for airborne LiDAR data: a review of critical issues. Remote Sens. 2010;2(3): 833-60. doi:10.3390/rs2030833.

12. Dralle K, Rudemo M. Stem number estimation by kernel smoothing of aerial photos. Can J For Res. 1996;26(7):1228-36. doi:10.1139/x26-137.

13. Gougeon FA. A crown-following approach to the automatic delineation of individual tree crowns in high spatial resolution aerial images. Can J Remote Sens. 1995;21(3):274-84. doi:10.1080 /07038992.1995.10874622.

14. Pollock RJ. The automatic recognition of individual trees in aerial images of forests based on a synthetic tree crown image model [monography]. Vancouver, Canada: University of British Columbia; 1996.

15. Pouliot DA, King DJ, Bell FW, Pitt DG. Automated tree crown detection and delineation in high-resolution digital camera imagery of coniferous forest regeneration. Remote Sens Environ. 2002;82(2-3):322-34. doi:10.1016/S0034-4257(02)00050-0.

16. Persson Å, Holmgren J, Söderman U. Detecting and measuring individual trees using an airborne laser scanner. Photogramm Eng Remote Sens. 2002;68(9):925-32.

17. Popescu SC, Wynne RH, Nelson RF. Estimating plot-level tree heights with LiDAR: local filtering with a canopy-height based variable window size. Comput Electron Agric. 2002;37(1-3):71-95.

18. Lindeberg T. Scale-space theory: a framework for handling image structures at multiple scales. In: Proc. CERN School of Computing; 1996; Egmond aan Zee, The Netherlands.

19. Wolf B-M, Heipke C. Automatic extraction and delineation of single trees from remote sensing data. Mach Vis Appl. 2007;18(5): 317-30. doi:10.1007/s00138-006-0064-9.

20. Bian YS, Zou P, Shu YH, Yu RH. Individual tree delineation in deciduous forest areas with LiDAR point clouds. Can J Remote Sens. 2014;40(2):152-63. doi:10.1080/07038992.2014.943700.

21. Falkowski MJ, Smith AMS, Hudak AT, Gessler PE, Vierling LA, Crookston NL. Automated estimation of individual conifer tree height and crown diameter via two-dimensional spatial wavelet analysis of LiDAR data. Can J Remote Sens. 2006;32(2):153-61. 
22. Axelsson PE. Processing of laser scanner data - algorithms and applications. ISPRS J Photogramm Remote Sens. 1999;54(2-3):138-47.

23. Holmgren J, Lindberg E. Tree crown segmentation based on a geometric tree crown model for prediction of forest variables. Can $\mathrm{J}$ Remote Sens. 2013;39:S86-98. doi:10.5589/m13-025.

24. Van Leeuwen M, Coops NC, Wulder MA. Canopy surface reconstruction from a LiDAR point cloud using Hough transform. Remote Sensing Letters. 2010;1(3):125-32. doi:10.1080 /01431161003649339.

25. Duncanson LI, Cook BD, Hurtt GC, Dubayah RO. An efficient, multi-layered crown delineation algorithm for mapping individual tree structure across multiple ecosystems. Remote Sens Environ. 2014;154:378-86. doi:10.1016/j.rse.2013.07.044.

26. Paris C, Valduga D, Bruzzone L. A hierarchical approach to three-dimensional segmentation of LiDAR data at single-tree level in a multilayered forest. IEEE Trans Geosci Remote Sens. 2016;54(7):4190-203.

27. Hirschmugl M. Derivation of Forest parameters from UltracamD data [Monography]. Graz, Austria: Graz University of Technology; 2008.

28. Tompalski P, Wężyk P, Weidenbach M, Kok Rd, Hawryło P. A comparison of Lidar and image-derived canopy height models for individual tree crown segmentation with object based image analysis. In: South-Eastern European Journal of Earth Observation and Geomatics; 2014. Saloniki, Grecja.

29. Waser LT, Ginzler C, Kuechler M, Baltsavias E, Hurni L. Semiautomatic classification of tree species in different forest ecosystems by spectral and geometric variables derived from Airborne Digital Sensor (ADS40) and RC30 data. Remote Sens Environ. 2011;115(1):76-85. doi:10.1016/j.rse.2010.08.006.

30. Kandare K, Dalponte M, Gianelle D, Chan JCW, Ieee. A new procedure for identifying single trees in understory layer using discrete LiDAR data. Ieee International Geoscience and Remote Sensing Symposium. IEEE International Symposium on Geoscience and Remote Sensing IGARSS, vol. 2014. New York: Ieee; 2014. p. 1357-60.

31. Tang S, Dong P, Buckles BP. Three-dimensional surface reconstruction of tree canopy from LiDAR point clouds using a region-based level set method. Int J Remote Sens. 2013;34(4):1373-85. doi:10.1080/01431161.2012.720046.

32. Bucksch A, Lindenbergh R, Abd Rahman MZ, Menenti M. Breast height diameter estimation from high-density airborne LiDAR data. IEEE Geosci Remote Sens Lett. 2014;11(6):1056-60. doi:10.1109 /lgrs.2013.2285471.

33. Lu X, Guo Q, Li W, Flanagan J. A bottom-up approach to segment individual deciduous trees using leaf-off LiDAR point cloud data. ISPRS J Photogramm Remote Sens. 2014;94:1-12. doi:10.1016/j. isprsjprs.2014.03.014.

34. Lindberg E, Eysn L, Hollaus M, Holmgren J, Pfeifer N. Delineation of tree crowns and tree species classification from full-waveform airborne laser scanning data using 3-D ellipsoidal clustering. IEEE Journal of Selected Topics in Applied Earth Observations and Remote Sensing. 2014;7(7):3174-81. doi:10.1109 /JSTARS.2014.2331276.

35. Mongus D, Žalik B. An efficient approach to 3D single tree-crown delineation in LiDAR data. ISPRS J Photogramm Remote Sens. 2015;108:219-33. doi:10.1016/j.isprsjprs.2015.08.004.

36. Reitberger J, Schnorr C, Krzystek P, Stilla U. 3D segmentation of single trees exploiting full waveform LiDAR data. ISPRS J Photogramm Remote Sens. 2009;64(6):561-74. doi:10.1016/j. isprsjprs.2009.04.002.

37. Morsdorf F, Meier E, Allgöwer B, Nüesch D. Clustering in airborne laser scanning raw data for segmentation of single trees. In: Maas HG, Vosselman G, Streilein A, editors. International Archives of the Photogrammetry, Remote Sensing and Spatial Information Sciences; 2003; Dresden, Germany.
38. Gupta S, Weinacker H, Koch B. Comparative analysis of clustering-based approaches for 3-D single tree detection using airborne fullwave LiDAR data. Remote Sens. 2010;2(4):968-89.

39. Ferraz A, Bretar F, Jacquemoud S, Goncalves G, Pereira L, Tome M, et al. 3-D mapping of a multi-layered Mediterranean forest using ALS data. Remote Sens Environ. 2012;121:210-23. doi:10.1016/j. rse.2012.01.020.

40. Shi JB, Malik J. Normalized cuts and image segmentation. IEEE Trans Pattern Anal Mach Intell. 2000;22(8):888-905.

41. Yao W, Wei YZ. Detection of 3-D individual trees in urban areas by combining airborne LiDAR data and imagery. IEEE Geosci Remote Sens Lett. 2013;10(6):1355-9. doi:10.1109 /lgrs.2013.2241390.

42. Lee J, Cai X, Lellmann J, Dalponte M, Malhi Y, Butt N, et al. Individual tree species classification from airborne multisensor imagery using robust PCA. IEEE Journal of Selected Topics in Applied Earth Observations and Remote Sensing. 2016;9(6): 2554-67. doi:10.1109/jstars.2016.2569408.

43. Lee H, Slatton KC, Roth BE, Cropper Jr WP. Adaptive clustering of airborne LiDAR data to segment individual tree crowns in managed pine forests. Int J Remote Sens. 2010;31(1):117-39. doi:10.1080 /01431160902882561.

44. Vaughn NR, Moskal LM, Turnblom EC. Tree species detection accuracies using discrete point LiDAR and airborne waveform LiDAR. Remote Sens. 2012;4(2):377-403. doi:10.3390 /rs4020377.

45.• Wang Y, Hyyppä J, Liang X, Kaartinen H, Yu X, Lindberg E, et al. International benchmarking of the individual tree detection methods for modeling 3D canopy structure for silviculture and forest ecology using airborne laser scanning. IEEE Trans Geosci Remote Sens. 2016;54(9):5011-27. An international benchmarking of five recently developed individual tree detection (ITD) methods based on high-density ALS data from two boreal forest test sites.

46. Vega C, Hamrouni A, El Mokhtari S, Morel J, Bock J, Renaud JP, et al. PTrees: a point-based approach to forest tree extraction from LiDAR data. Int J Appl Earth Obs Geoinf. 2014;33:98-108. doi:10.1016/j.jag.2014.05.001.

47. Kaartinen H, Hyyppä J, Yu X, Vastaranta M, Hyyppä H, Kukko A, et al. An international comparison of individual tree detection and extraction using airborne laser scanning. Remote Sens. 2012;4(4): 950-74. An international comparison of fourteen automatic or semi-automatic tree extraction methods based on high-density ALS data from two boreal forest test sites.

48. Vauhkonen J, Ene L, Gupta S, Heinzel J, Holmgren J, Pitkanen J, et al. Comparative testing of single-tree detection algorithms under different types of forest. Forestry. 2012;85(1):27-40. doi:10.1093 /forestry/cpr051. An international comparison of six different algorithms for extraction of treetop positions based on ALS data from boreal forests in Norway and Sweden, coniferous and broadleaved forests in Germany and tropical pulpwood plantations in Brazil.

49. Eysn L, Hollaus M, Lindberg E, Berger F, Monnet J-M, Dalponte $\mathrm{M}$, et al. A benchmark of LiDAR-based single tree detection methods using heterogeneous forest data from the alpine space. Forests. 2015;6(5):1721. An international benchmarking of eight single tree detection methods based on ALS data from different forest regions in the Alpine Space.

50. Shinozaki K, Yoda K, Hozumi K, Kira T. A quantitative analysis of plant form; the pipe model theory, 1. Basic Analyses. Japanese Journal of Ecology. 1964;14(3):97-105.

51. Gaveau DLA, Hill RA. Quantifying canopy height underestimation by laser pulse penetration in small-footprint airborne laser scanning data. Can J Remote Sens. 2003;29(5): 650-7. doi: $10.5589 / \mathrm{m} 03-023$. 
52. Hyyppä J, Inkinen M. Detecting and estimating attributes for single trees using laser scanner. The photogrammetric journal of Finland. 1999; 16(2):27-42.

53. Olofsson K, Lindberg E, Holmgren J. A method for linking fieldsurveyed and aerial-detected single trees using cross correlation of position images and the optimization of weighted tree list graphs. In: Hill RA, Rosette J, Suárez J, editors. Proceedings of SilviLaser 2008, 8th international conference on LiDAR applications in forest assessment and inventory; 2008 17-19 September, 2008; HeriotWatt University, Edinburgh, UK. Bournemouth UK: SilviLaser 2008 Organizing Committee, Edinburgh: Forest Research.

54. Dorigo W, Hollaus M, Wagner W, Schadauer K. An applicationoriented automated approach for co-registration of forest inventory and airborne laser scanning data. Int J Remote Sens. 2010;31(5): 1133-53. doi:10.1080/01431160903380581.

55. Lindberg E, Holmgren J, Olofsson K, Olsson H. Estimation of stem attributes using a combination of terrestrial and airborne laser scanning. Eur J For Res. 2012;131(6):1917-31. doi:10.1007/s10342012-0642-5.

56. Lindberg E, Holmgren J, Olofsson K, Olsson H, Wallerman J. Estimation of tree lists from airborne laser scanning data using a combination of analysis on single tree and raster cell level. In: Hill RA, Rosette J, Suárez J, editors. Proceedings of SilviLaser 2008, 8th international conference on LiDAR applications in forest assessment and inventory; 2008 17-19 September, 2008; HeriotWatt University, Edinburgh, UK. Bournemouth UK: SilviLaser 2008 Organizing Committee, Edinburgh: Forest Research.

57. Lindberg E, Holmgren J, Olofsson K, Wallerman J, Olsson H. Estimation of tree lists from airborne laser scanning using tree model clustering and k-MSN imputation. Remote Sens. 2013;5: 1932-55. doi:10.3390/rs5041932.

58. Flewelling JW. Probability models for individually segmented tree crown images in a sampling context. In: Hill RA, Rosette J, Suárez J, editors. Proceedings of SilviLaser 2008, 8th international conference on LiDAR applications in forest assessment and inventory; 2008 17-19 September, 2008; Heriot-Watt University, Edinburgh, UK: SilviLaser 2008 Organizing Committee, Edinburgh: Forest Research.

59. Breidenbach J, Næsset E, Lien V, Gobakken T, Solberg S. Prediction of species specific forest inventory attributes using a nonparametric semi-individual tree crown approach based on fused airborne laser scanning and multispectral data. Remote Sens Environ. 2010;114(4):911-24. doi:10.1016/j.rse.2009.12.004.

60. Holmgren J, Barth A, Larsson H, Olsson H. Prediction of stem attributes by combining airborne laser scanning and measurements from harvesters. Silva Fennica. 2012;46(2):227-39.

61. Wallerman J, Bohlin J, Fransson JES. Forest height estimation using semi-individual tree detection in multi-spectral 3D aerial DMC data. 2012 Ieee International Geoscience and Remote Sensing Symposium. IEEE International Symposium on Geoscience and Remote Sensing IGARSS, 2012. 6372-5.

62. Brandtberg T, Warner TA, Landenberger RE, McGraw JB. Detection and analysis of individual leaf-off tree crowns in small footprint, high sampling density LiDAR data from the eastern deciduous forest in North America. Remote Sens Environ. 2003;85(3):290-303. doi:10.1016/s0034-4257(03)00008-7.

63. Holmgren J, Persson Å. Identifying species of individual trees using airborne laser scanner. Remote Sens Environ. 2004;90(4):415-23. doi:10.1016/s0034-4257(03)00140-8.

64. Donoghue DNM, Watt PJ, Cox NJ, Wilson J. Remote sensing of species mixtures in conifer plantations using LiDAR height and intensity data. Remote Sens Environ. 2007;110(4):509-22. doi:10.1016/j.rse.2007.02.032.

65. Ørka HO, Næsset E, Bollandsås OM. Classifying species of individual trees by intensity and structure features derived from airborne laser scanner data. Remote Sens Environ. 2009;113(6): 1163-74. doi:10.1016/j.rse.2009.02.002.

66. Holmgren J, Persson $\AA$, Söderman U. Species identification of individual trees by combining high resolution LiDAR data with multi-spectral images. Int J Remote Sens. 2008;29(5):1537-52. doi:10.1080/01431160701736471.

67. Vauhkonen J, Tokola T, Maltamo M, Packalén P. Effects of pulse density on predicting characteristics of individual trees of Scandinavian commercial species using alpha shape metrics based on airborne laser scanning data. Can J Remote Sens. 2008;34:441-59.

68. Vauhkonen J, Tokola T, Packalén P, Maltamo M. Identification of Scandinavian commercial species of individual trees from airborne laser scanning data using alpha shape metrics. For Sci. 2009;55(1):37-47.

69. Ko C, Sohn G, Remmel T. A Comparitive study using geometric and vertical profile features derived from airborne LiDAR for classification tree genera. In: Shortis M, Wagner W, Hyyppä J, editors. International Archives of the Photogrammetry, Remote Sensing and Spatial Information Sciences; 201225 August-1 September, 2012; Melbourne, Australia.

70. Heinzel J, Koch B. Investigating multiple data sources for tree species classification in temperate forest and use for single tree delineation. Int J Appl Earth Obs Geoinf. 2012;18:101-10. doi:10.1016/j.jag.2012.01.025.

71. Dalponte M, Ørka HO, Ene LT, Gobakken T, Næsset E. Tree crown delineation and tree species classification in boreal forests using hyperspectral and ALS data. Remote Sens Environ. 2014;140: 306-17. doi:10.1016/j.rse.2013.09.006.

72. St-Onge B, Budei BC. Individual tree species identification using the multispectral return intensities of the Optech Titan LiDAR system. In: Durrieu S, Véga C, editors. SilviLaser 2015; 2015 September 28-30, 2015; La Grande Motte, France.

73. Reitberger J, Krzystek P, Stilla U. Analysis of full waveform LiDAR data for the classification of deciduous and coniferous trees. Int J Remote Sens. 2008;29(5):1407-31. doi:10.1080 /01431160701736448.

74. Heinzel J, Koch B. Exploring full-waveform LiDAR parameters for tree species classification. Int J Appl Earth Obs Geoinf. 2011;13(1): 152-60. doi:10.1016/j.jag.2010.09.010.

75. Reitberger J, Krzystek P, Stilla U. 3D segmentation and classification of single trees with full waveform LiDAR data. In: Hill RA, Rosette J, Suárez J, editors. Proceedings of SilviLaser 2008, 8th international conference on LiDAR applications in forest assessment and inventory; 2008 17-19 September, 2008; Heriot-Watt University, Edinburgh, UK: SilviLaser 2008 Organizing Committee, Edinburgh: Forest Research.

76. Zhang CY, Zhou YH, Qiu F. Individual tree segmentation from LiDAR point clouds for urban forest inventory. Remote Sens. 2015;7(6):7892-913. doi:10.3390/rs70607892.

77. Lindberg E, Roberge J-M, Johansson T, Hollaus M, Holmgren J, Hjältén J. Individual tree properties from ALS data as input to habitat analysis in boreal forest. In: Durrieu S, Véga C, editors. SilviLaser 2015; 2015 September 28-30, 2015; La Grande Motte, France: IGN, LIF, Saint-Mandé Cedex, France.

78. Casas A, Garcia M, Siegel RB, Koltunov A, Ramirez C, Ustin S. Burned forest characterization at single-tree level with airborne laser scanning for assessing wildlife habitat. Remote Sens Environ. 2016;175:231-41. doi:10.1016/j.rse.2015.12.044.

79. Briese C, Pfennigbauer M, Lehner H, Ullich A, Wagner W, Pfeifer N. Radiometric calibration of multi-wavelength airborne laser scanning data. In: Shortis M, Wagner W, Hyyppä J, editors. International Archives of the Photogrammetry, Remote Sensing and Spatial Information Sciences; 201225 August-1 September, 2012; Melbourne, Australia. 
80. Optech T. Optech titan multispectral LiDAR system. Teledyne Optech. Vaughan ON, Canada: In; 2015 .http://www. teledyneoptech.com/wp-content/uploads/Titan-Specsheet-150515WEB.pdf

81. Petrie G. Airborne topographic laser scanners: current developments in the technology. Geoinformatics. 2011;14(1):34-44.

82. RIEGL. RIEGL VQ-580. RIEGL Laser Measurement Systems GmbH. Horn, Austria. 2012 .http://www.riegl.com/uploads/tx pxpriegldownloads/10_DataSheet_VQ-580_02-04-2012_ PRELIMINARY.pdf.

83. RIEGL. RIEGL LMS-Q680i. RIEGL Laser Measurement Systems GmbH. Horn, Austria. 2012. http://www.riegl.com/uploads/tx pxpriegldownloads/10 DataSheet LMS-Q680i_04-04-2012_01.pdf.

84. RIEGL. RIEGL VQ-820 G. RIEGL Laser Measurement Systems GmbH. Horn, Austria. 2012. http://www.riegl.com/uploads/tx pxpriegldownloads/10_DataSheet_VQ-820-G_05-04-2012 PRELIMINARY.pdf.

85. Lillesand T, Kiefer RW, Chipman J. Remote sensing and image interpretation. 6th edition ed. New York: John Wiley \& Sons, Inc; 2007.

86. Hakala T, Suomalainen J, Kaasalainen S, Chen Y. Full waveform hyperspectral LiDAR for terrestrial laser scanning. Opt Express. 2012;20(7):7119-27. doi:10.1364/OE.20.007119.

87. Lindberg E, Briese C, Doneus M, Hollaus M, Schroiff A, Pfeifer N. Multi-wavelength airborne laser scanning for characterization of tree species. In: Durrieu S, Véga C, editors. SilviLaser 2015; 2015
September 28-30, 2015; La Grande Motte, France: IGN, LIF, Saint-Mandé Cedex, France.

88. Hakala T, Nevalainen O, Kaasalainen S, Makipaa R. Technical Note: multispectral LiDAR time series of pine canopy chlorophyll content. Biogeosciences. 2015;12(5):1629-34. doi:10.5194/bg-121629-2015.

89. Wallace A, Nichol C, Woodhouse I. Recovery of forest canopy parameters by inversion of multispectral LiDAR data. Remote Sens. 2012;4(2):509-31. doi:10.3390/rs4020509.

90. Woodhouse IH, Nichol C, Sinclair P, Jack J, Morsdorf F, Malthus TJ, et al. A multispectral canopy LiDAR demonstrator project. IEEE Geosci Remote Sens Lett. 2011;8(5):839-43. doi:10.1109 /lgrs.2011.2113312.

91. Gong W, Song SL, Zhu B, Shi S, Li FQ, Cheng XW. Multiwavelength canopy LiDAR for remote sensing of vegetation: design and system performance. ISPRS J Photogramm Remote Sens. 2012;69:1-9. doi:10.1016/j.isprsjprs.2012.02.001.

92. Stoker J, Abdullah Q, Nayegandhi A, Winehouse J. Evaluation of single photon and Geiger mode Lidar for the 3D Elevation Program. Remote Sens. 2016;8(9):767.

93. Swatantran A, Tang H, Barrett T, DeCola P, Dubayah R. Rapid, high-resolution forest structure and terrain mapping over large areas using single photon lidar. Scientific Reports. 2016;6:28277. doi:10.1038/srep28277. http://www.nature.com/articles/srep28277 \#supplementary-information 